\title{
Do We Need Hygrothermal Simulations to Evaluate the Design for Durability?
}

\author{
Martin Morelli ${ }^{1}$ and Erik Brandt ${ }^{2}$ \\ ${ }^{1}$ Department of the Built Environment, Aalborg University, A.C. Meyers Vænge 15, 2450 \\ Copenhagen, Denmark, marmo@build.aau.dk \\ ${ }^{2}$ Department of the Built Environment, Aalborg University, A.C. Meyers Vænge 15, 2450 \\ Copenhagen, Denmark, ebra@build.aau.dk
}

\begin{abstract}
The Danish Building regulations are function based and describe in broad terms which requirements must be fulfilled. The main message is that buildings and their structures must be built in such a way that they have a satisfactory functionality and durability i.e. that materials and constructions used can resist the stresses they are exposed to under use. However, there are no Danish guidelines on how to document fulfillment of the requirements. Durability largely depends on moisture related problems, and many failure modes/mechanisms are linked to moisture conditions. It is a prerequisite that the hygrothermal performance of a building component is satisfactory if a long service life shall be obtained. The paper will demonstrate how the risk of moisture problems is assessed in Denmark by using a stud wall as an example. However, simulations can be used for documenting the expected performance of wall assemblies, under in use conditions, however is not a conditional necessity. Even though an evaluation or simulation of moisture conditions show satisfactory results problems can occur e.g. if unsuited materials are used or if materials or building elements are used in another way than foreseen. A few examples are shown how simulations could and could not be used to determine whether a structure would have a long service life or not. Finally, a comparison of simulations, calculations and measurements are performed to illustrate the difference in results from moisture assessment that can be achieved based on assessment methodology.
\end{abstract}

Keywords: Performance Criteria, Assessment of Durability, Documentation, Function-Based, Moisture Simulation.

\section{Introduction}

Durability of building materials, components or elements is a crucial parameter in the design of buildings with a long service life. To design for durability, it is necessary to consider which environment the building element is located in, the agents that can degrade the materials and in case of degradation how to maintain or repair the building element (ISO, 2008; Morelli and Lacasse, 2019). Moisture damage is perhaps one of the most critical agents limiting the building's service life causing premature degradation of building elements (Nevalainen et al., 2010; Becher et al., 2017) and contamination of indoor environment (Hägerhed-Engman, Bornehag and Sundell, 2009). A too high moisture content for too long can cause degradation of components inside building elements and/or biological growth of e.g. mould. Consequently, studying the coupled heat and moisture transport in structures is essential to improve or document the performance of the building envelope.

This paper presents a number of methods that might be applicable to document the service life as required in the Danish Building regulations (BR, 2019) related to moisture problems. 
Furthermore, the paper will discuss if hygrothermal simulations are needed for evaluating the durability of the design of structures. Using an exterior wooden-stud wall as example, the paper discusses how the risk of moisture problems can be assessed applying different methodologies. Furthermore, calculations/simulations are compared to measurements conducted in the stud wall, to illustrate how the documentation of the expected performance can be conducted. Finally, two examples are presented on failure mechanisms, where unsuited materials or design is used for a given outdoor climate.

\subsection{Prescriptive or Performance-Based Building Regulations}

During the past decades, the Danish building regulations have amended from prescriptive building regulations towards performance-based regulations. Gottlieb and Frederiksen (2019) mention the accelerating development of new products and materials as contributing to change the building regulations towards performance-based requirements. The development from prescriptive to performance-based regulations are seen in the building style of older apartment buildings in Copenhagen. Many old buildings constructed around 1900 have similar façade appearance because the building regulations had prescriptive requirements related to the building design; whereas the appearance of today's building stock is more varying. The performance-based regulations describe the functional attributes that e.g. building components must fulfill. These requirements can be achieved with several designs; i.e. the regulations do not any more describe how to build but rather what performance the finished buildings shall

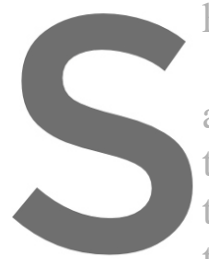
have.

\section{The chapter of the building regulations related to energy} allowable energy consumptio threshold for the U-values the regulations only descris they have a satisfactory
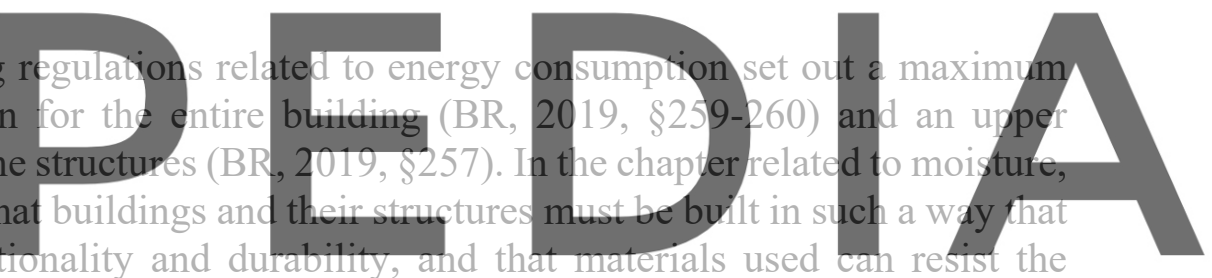

environment they are exposed to (BR, 2019, \$334). The energy and moisture examples illustrate

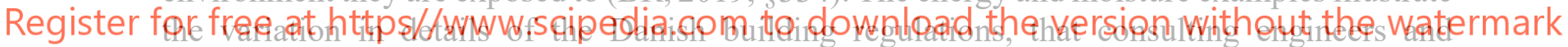

architects faces (hereafter referred to as designers). On the one hand, exact energy requirements are given (and there exist a tool to use for documentation); however, on the other hand there is no methodology to document that moisture will not result in moisture problems in the structure or indoor climate. Regarding documentation of moisture related properties, the designer can perform, e.g. Glaser method calculation (Glaser, 1958) or detailed hygrothermal simulations in $1 \mathrm{D}$ or $2 \mathrm{D}$; however, it is up to the designers to decide on the level of documentation for whether the structures comply with the building regulations. A random check is performed in $10 \%$ of building projects with occupation permit, however, the random check does not necessary include an evaluation of the moisture documentation.

\section{Methods for Assessing Moisture Problems}

Designers of structures can use a variety of methods to support or document that the structure is durable regarding moisture exposure under in use conditions. However, the different methods all have limitations. The authors understand that the methods described below are those most commonly used in Denmark. The approaches are ranked from simple to complex, and can be used to evaluate the risk of moisture problems, where mould growth is considered the first 
indication of a mediocre structure design, which can contribute to health problems indoors.

1. "Common best practice" or learn from experience. This is normally supported by guidelines (e.g. www.anvisninger.dk) and experience documents (e.g. Building defect sheets, www.byg-erfa.dk) made on basis of experience from the use in practice. Normally, materials and building elements described in this literature function satisfactory under the given climate condition etc. No calculations or further documentation for properties is needed.

2. Simulation of isotherms combined with determination of the point where the relative humidity exceed $75 \%$ or condensation. This is used in more complex structures of 2D problems. Combined with considerations of the indoor environment and temperatures in the construction this is a simple evaluation method. The designer has to decide on the evaluation criteria of a given relative humidity, which normally is set to $75 \%$.

3. Glaser calculation according to EN 13788 (EN ISO, 2012). This includes calculation of surface and interstitial condensation including drying out of the structure or evaluation of critical points exceeding 75\% relative humidity. Glaser is used on 1D problems.

4. Hygrothermal simulations in $1 D$ or $2 D$. In more complex structures simulation programs can be used to determine the conditions in the structure and on all internal surfaces. This method is the most comprehensive approach for assessing moisture conditions in building elements. However, the results are to be post-processed with another evaluation tool.

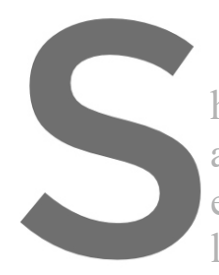

Depending on the humidity exceed a threst are developed to evelute exposure of high moisture toat for th level and material are considered. For organic

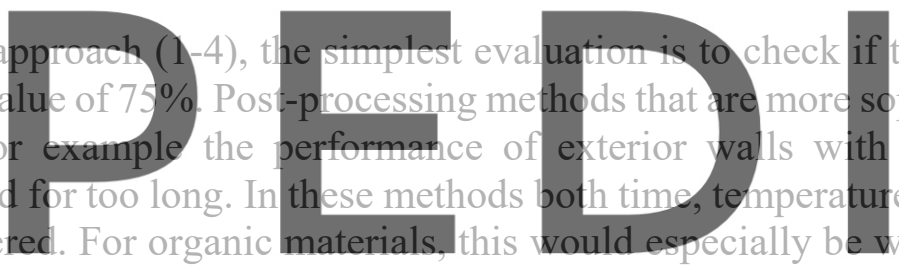
A to evaluating the risk of mould growth and/or wood rot, whereas for inorganic porous materials

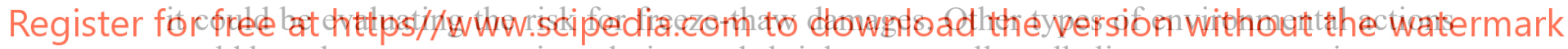
could be subterranean termites, drying and shrinkage as well as alkali-aggregate reactions.

\section{Example of Measurements, Calculation and Simulation}

In this example, we consider an exterior wood-stud wall constructed with $465 \mathrm{~mm}$ glass-fiber insulation as shown in Figure 1 and installed in a single-family house. The vapour barrier was mounted behind the first inside insulation layer. In the wall, measuring devices were installed to measure temperature and relative humidity. The measuring points were located in the interior insulation against the vapour barrier and in the exterior insulation against the plywood board. The measurements were conducted from October 2013 to March 2014.

\subsection{Boundary Conditions}

The Glaser calculation used boundary conditions from October to March; i.e. monthly average values of temperature and relative humidity for Denmark and internal humidity class 2 (EN ISO, 2012) for the interior climate, see Table 1. 

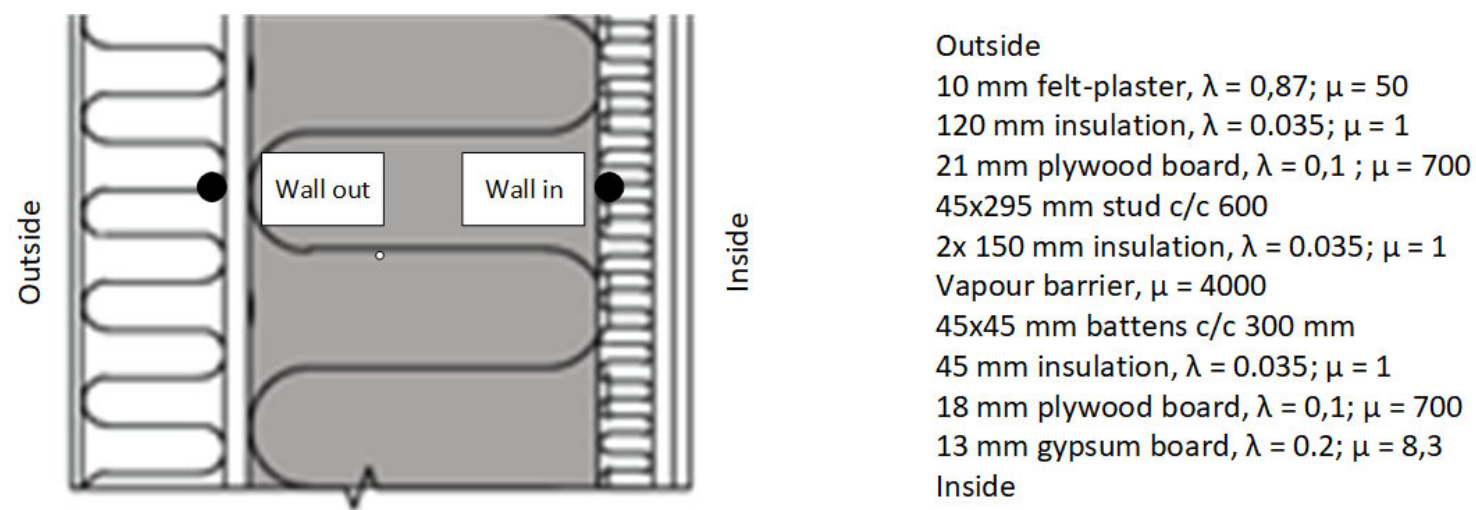

Figure 1. Exterior wood-stud wall with $465 \mathrm{~mm}$ insulation.

Table 1. Climate data for Glaser calculation. Temperature in ${ }^{\circ} \mathrm{C}$ and relative humidity in $\%$.

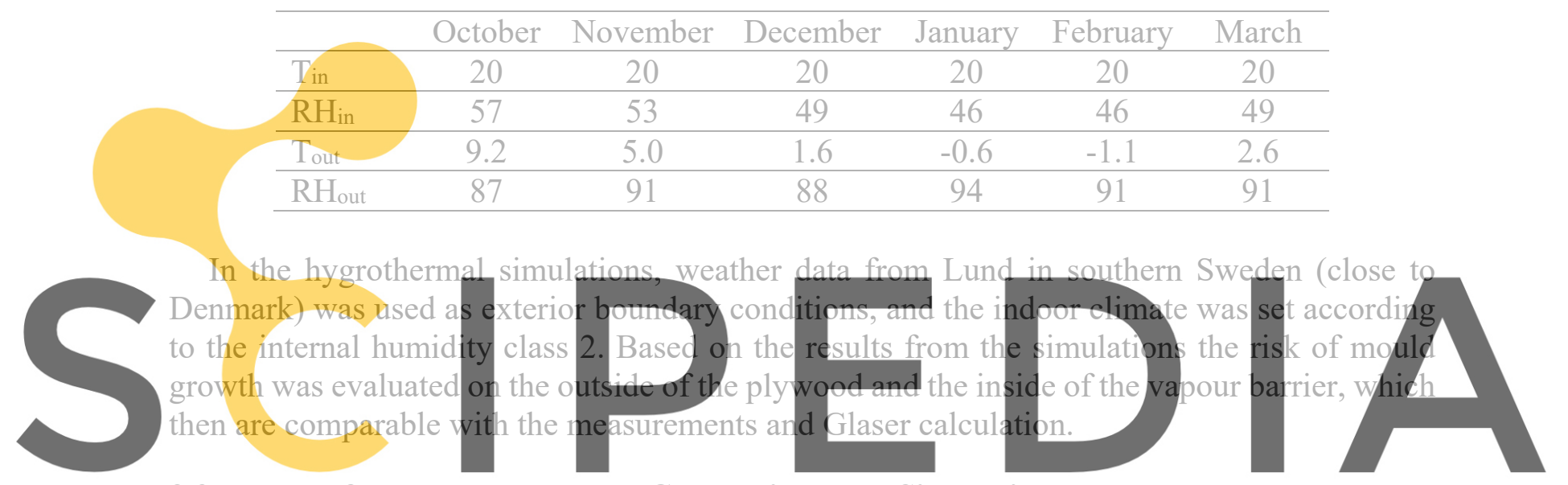

3.2 Results from Measurements, Calculations and Simulations

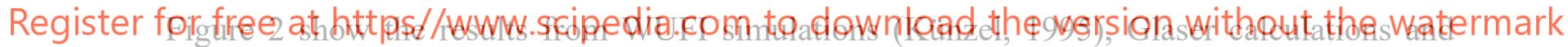
measurements for the period October to March. The results are not a validation of the three methods but only a way of illustrating how different approaches can bring different results.

\section{Discussion}

Designing for durability requires that designers consider several aspects where some information is difficult to predict e.g. climate changes and some are unknown e.g. material properties of new products. de Place Hansen et al. (2020) present a systematic review of new products used in building envelope structures, aiming at reducing the risk of using unsuited materials.

Using common best practice documents for design is based on many years of experience. However, the conditions under which the building elements perform is retrospective and the used materials and components are well known. Therefore, one might question how these structures will perform in the future with expected climate changes. These common best practice designs of the building envelope, further presume that built-in moisture is very limited, and that eaves protect the walls. The common best practice designs do not require documentation of the long-term performance, as this is implicit in the documents published. 


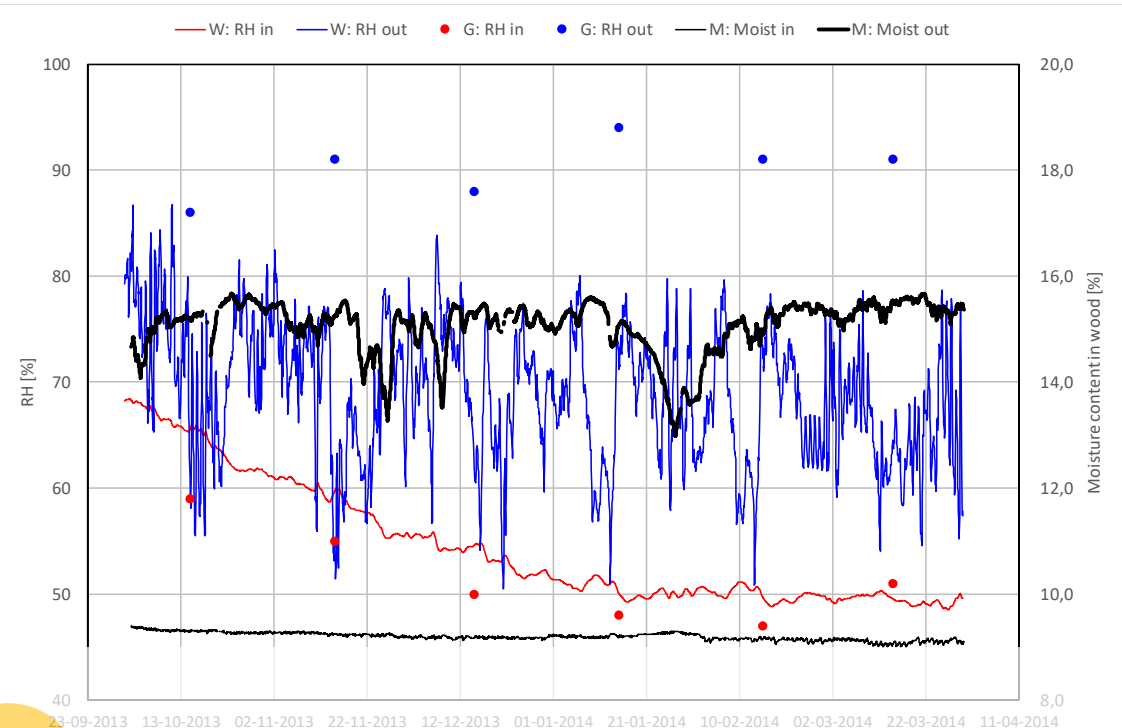

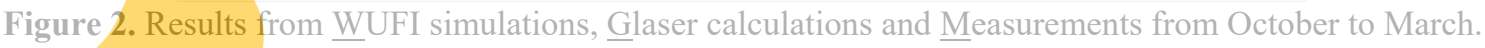

Considering the other three methods (isotherm -, Glaser calculations and hygrothermal simulations) presented for assessing moisture problems in structures, all take into account interior and exterior boundary conditions differently. In a Danish context, the different methods are challenged by the different outdoor climate used, e.g. that Glaser calculation uses monthly average values of temperature for a Danish reference year. Danish weather data do for hygrothermal simulations where rain data are included. Therefore, weather dat Sweden or Germany are used, as these a calculations only consider temperature.

The climate that the building envelope is exposed to
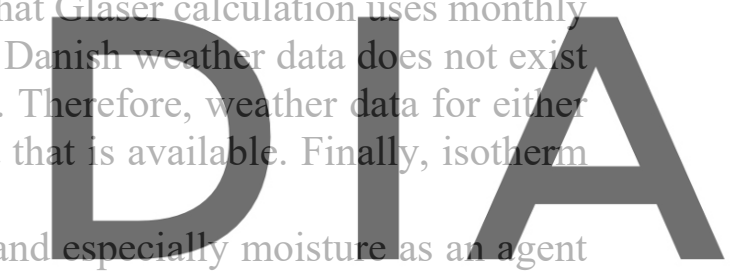
that might reduce the durability - is perhaps the most important. Therefore, moisture exposure

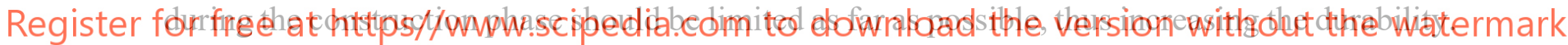

The application of the four approaches are presented as methodologies for assessing the moisture durability of building envelope structure. Depending on the complexity of the structure or (un)known materials, one of the four approaches could be used for documenting the moisture durability, see Figure 3.

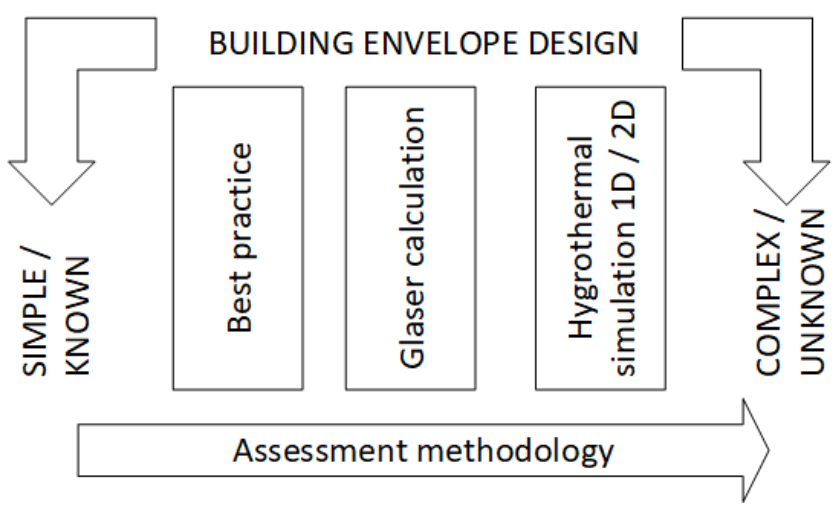

Figure 3. Example of an approach on how to document the moisture durability depending on complexity or (un)known materials. 
Hygrothermal simulations are highly relevant in the toolbox of the designer when assessing the durability of building envelope structures. Therefore, it is important to investigate how the building envelope perform under future climate conditions. Performing simulations with a varying climate e.g., as in Canada using cycles of wet-wet-dry years, future climates as can be found under Climate for Culture (a project that investigating the potential impact of climate change on Europe's cultural heritage assets) or weather data with 50 years of occurrence might be needed. Nevertheless, investigating the structure with a retrospective outdoor climate file for several continuous years seems to be insufficient.

In Denmark, the use of hygrothermal simulations become more popular in the design of new structures. However, there exist no guidelines on how to approach such a task and how to assess the output from the simulations. Therefore, the documentation of the requirements in the building regulations depends on the individual designer. The authors suggest that a guideline for design for durability is developed in Denmark. Such a guideline could be inspired by the "Guideline on design for durability of building envelopes" (Lacasse et al., 2018) that is suggested to be implemented in the Canadian building codes. The guideline seems to be reasonable when having known materials that are built together in a different way as described in the common best practice documents. However, the application of the methodology is a challenge when new products are brought to the market that are not already incorporated in hygrothermal simulation programs or for which relevant material properties are not available here a best estimation must be performed based on the known properties. New materials could be developed for a specific function in a stud wall, however the designer or contractor might suggest to use this new misused leading to maj to detect using hygrothe

Performing assessinent of are anchored in the nat
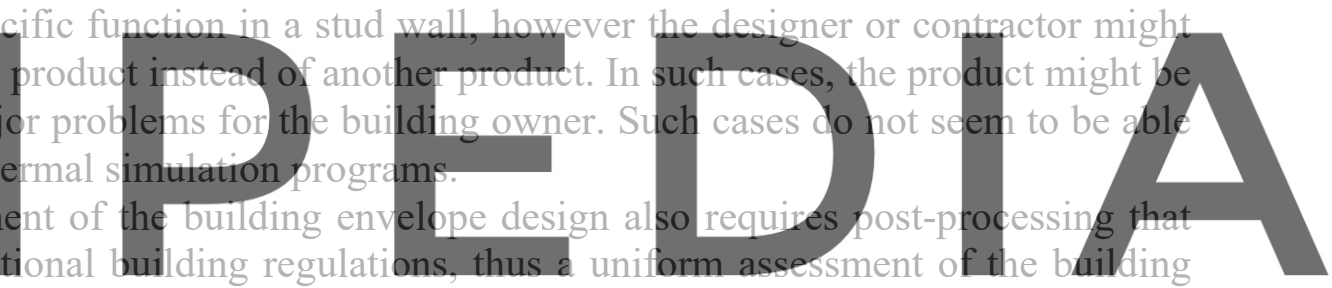

envelope design for durability can be performed by different designers across the country, such

\subsection{Example of Problems Despite Good Results of Moisture Assessment}

Even though an evaluation or simulation of moisture conditions show satisfactory results problems can occur e.g. if unsuited materials are used or if materials or building elements are used in another way than foreseen. A couple of examples are given below to illustrate the problems that may be encountered.

\subsubsection{Use of MgO boards as wind barrier}

$\mathrm{MgO}$ boards were introduced in Denmark for use as wind barriers in facades etc. around 20092010. Several different suppliers described the material as well suited for the use. The boards had many good properties including permeability, strength, weight, fire properties, workability and price. Due to the price and workability, the boards quickly became popular and gained a good market share even though there was not sufficient impartial documentation. After about five years problems started to occur. The use of boards as wind barrier meant that the boards were exposed to high relative humidity in longer periods of the year. This caused problems as the boards contains salt, which absorbs moisture until the boards start to "cry", i.e. salty water 
was running from the boards. This caused problems with increased moisture levels in the neighboring materials, corrosion of fastener, screws etc. and mould growth.

The main problem here was that the degradation mechanisms for the material were not identified before the products was used. In this case, an identification of the properties of the board could have revealed that it was not able to withstand the environment in which it was envisaged to be used. A simulation of the moisture content on the wind barrier could have been used to identify the conditions the product would be exposed to.

\subsubsection{Use of building elements in harsher environment}

In Denmark moisture simulations and full scale tests have shown that wooden facades under certain conditions may be used without ventilation behind the outer cladding.

Recently, the Danish Building Research Institute was asked if the construction also were suited for use in a summer cottage near a coastline exposed to a lot of severe wind (and consequently a lot of driving rain). In this case, a construction tested under conditions simulating a heated house exposed to "normal" wind was proposed to be used under quite different conditions, i.e. no heating in winter time and therefore no vapour pressure to remove moisture from the wall, and at the same time risk of more water penetrating through the cladding due to the increased driving rain exposure.

The main problem here is that a correct assessment or simulation is not used - the result of the assessment might be quite different in the less favourable environment. Of importance is that one must understa those results before apply

\subsubsection{Degradation ine} In order to make a good overall evaluation
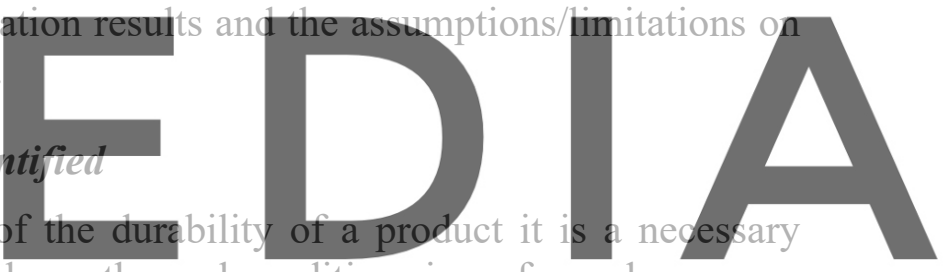

condition that an assessment/simulation of the hygrothermal conditions is performed.

Register for frewever this is hot a sufficient.condition as it is also necessary to. identify the degradation mechanism of the material or building component and the anticipated assemblies these are envisioned to be used in. The degradation mechanism may be identified partly based on knowledge about the material(s) used. Further, it should be investigated what the functions are of the product, which environment it will be used in (what is the product exposed to) and which properties are necessary.

To ensure long service life materials or building elements should be chosen so they have the sufficient properties. Proof of this should be documented by testing/evaluation of an impartial body.

In case the use conditions are changed as mentioned in the above example (4.1.2) or if the product is envisaged to be used for quite other purposes - i.e. with new functions - a new investigation of degradation mechanisms has to be performed as, exposure to another environment must be expected and the necessary properties therefore may be different.

\section{Conclusion}

To conclude, the authors do not believe that hygrothermal simulations always is the way of documenting building envelope design for its durability. However, the simulations are a strong tool to support the documentation and investigation of new structures that consist of known 
materials and components. In any case, the designer must first determine the agents effecting the durability, and then decide how this can be documented e.g. applying hygrothermal simulations. Using new materials, the authors do not believe that environmental actions such as agents causing corrosion or decay always are identified as this depends on the designer knowledge. Furthermore, action effects are not necessary made visible through the simulations as new materials are not tested and available in hygrothermal simulation programs. In such cases, the simulations can be used to determine the microclimate that the new product is placed in and its required properties to secure a long service life.

The authors suggest, that in the Danish context, a Guideline on design for durability of building envelope is developed and guidelines for assessing results from hygrothermal simulations. Such two guidelines will be a valuable support for designers when they have to document the durability of structures according to the requirements in the performance-based building regulation. The authors outlined a framework for an approach on how to combine moisture assessment methodologies to the complexity of building envelope structures.

ORCID

Martin Morelli: https://orcid.org/0000-0002-1013-3136

Erik Brandt: https://orcid.org/0000-0003-1485-5600

References

Becher, R., Høie, A.H., Bakke, J.V., Holøs, S.B. and Øvrevik, J. (2017). Dampness and Moisture Problems in

Norwegian Homes. J En

BR (2019). Danish Building

EN ISO (2012). EN ISO

Internal surface temperat

methods.

Glaser, H. (1958). Vereinfachte Berechnung der Dampfc
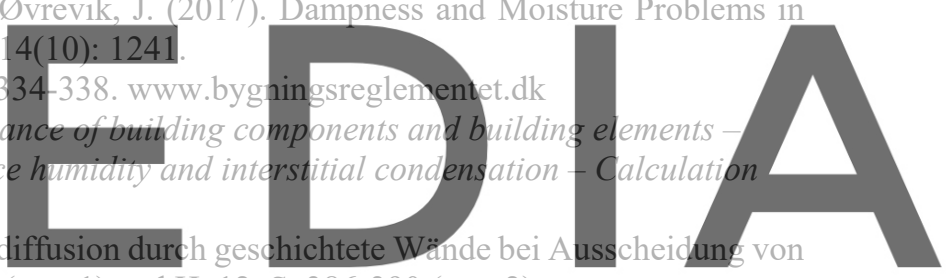

Wasser und Eis. Kältetechnik 10, H. 11, S. 358-364 (part 1) and H. 12, S. 386-390 (part 2).

Gottlieb, S.C. and Frederiksen, N. (2019). Deregulation as socio-spatial transformation: Dimensions and

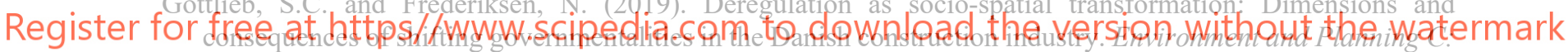
Politics and Space.

Hägerhed-Engman, L., Bornehag, C.-G. and Sundell, J. (2009). Building characteristics associated with moisture related problems in 8,918 Swedish dwellings. International Journal of Environmental Health Research, 19(4): 251-265.

de Place Hansen, E.J., Nielsen, J., Møller, E.B. and. Peuhkuri, R.H. (2020). How to Determine when a New Building Product is Suitable - Certifications and Experience. In Proceedings of XV International Conference on Durability of Building Materials and Compponents, Barcelona, Spain.

ISO (2008). ISO 13823 General principles on the design of structures for durability.

Künzel, H.M. (1995). Simultaneous heat and moisture transport in building components. One- and twodimensional calculation using simple parameters. Fraunhofer IRB Verlag, Stuttgart

Lacasse, M.A., Ge, H., Hegel, M., Jutras, R., Laouadi, A., Sturgeon, G. and Wells, J. (2018). Guideline on design for durability of building envelopes. Report CRBCPI-Y2-R19. NRC, Construction.

Morelli, M. and Lacasse, M.A. (2019). A Systematic methodology for design of retrofit actions with longevity. Journal of Building Physics, 42(4): 585-604.

Nevalainen, A., Partanen, P., Jääskeläinen, E., Hyvärinen, A., Koskinen, O., Meklin, T., Vahteristo, M., Koivisto, J. and Husman, T. (2010). Prevalence of Moisture Problems in Finnish Houses. Indoor Air, 8(S4): pp-pp.

Overton G. (2019). Hygrothermal performance of New Zealand wall constructions - meeting the durability requirements of the New Zealand Building Code. Canadian Journal of Civil Engineering, 46(11). 